\title{
Fabricantes y trabajadores en el siglo XIX (1850: motín de Tarel)
}

\section{Carlos Illades}

\author{
La desobediencia, a los ojos de cualquiera que \\ haya leido historia, es la virtud original del hombre.
}

Oscar Wilde

$\mathrm{E}$ l estudio de la historia de México del siglo xix tiene una complejidad especial: no sólo ocurren cambios de gran importancia en el Estado (que deviene capitalista), sino que la base económica de la sociedad sufre transformaciones considerables, abriéndose con ello una verdadera época de revolución social.

Desde comienzos del siglo xix se observa el proceso de destrucción del artesanado. Será necesario que transcurran varias décadas para que estos trabajadores logren un nivel de organización que les permita enfrentar, en mejores condiciones, las secuelas de este proceso.

En 1814 se lanzó una ofensiva en contra de los gremios, ${ }^{1}$ la cual, a corto plazo, tuvo como consecuencia la ruptura de los nexos entre el taller y la residencia del trabajador -el alejamiento del productor directo de los medios de producción-. Otra consecuencia importante en el proceso de desintegración de los gremios fue el cambio de relaciones entre los productores directos (artesanos), que ahora se mercantilizan en mayor escala.

Resultado de esta mercantilización fue la supresión de los exámenes para ascender dentro de la jerarquía reconocida por los gremios, lo que permitió la existencia — en los años siguientes- de "maestros" que poco o nada sabían del oficio pero que contaban con el dinero suficiente para alquilar un establecimiento y pagar a pequeños grupos de oficiales y jornaleros. Por otra parte, el aprendizaje, estrictamente reglamentado en la época colonial, pasó a ser una relación contractual entre el aprendiz (o sus padres) y el maestro. ${ }^{2}$ Por lo demás, el nivel de vida de los artesanos era bastante precario.

Al iniciarse la segunda mitad del siglo xIX quedan disueltos, formalmente, los gremios. Este hecho motivó la respuesta organizada de los artesanos: las sociedades de socorros mutuos. En 1839 se constituyó la primera sociedad mutualista de la cual tenemos noticia: la Sociedad Mercantil y de Seguridad de la Caja de Ahorros de Orizaba. Catorce años después, los trabajadores de la industria sombrerera organizaron la Sociedad Particular de Socorros Mutuos. ${ }^{3}$

I.“... .en 1813 las Cortes Extraordinarias de Cádiz propinaron un duro golpe a las agrupaciones gremiales al autorizar la libre explotación de la industria, la franquicia para establecer 'fábricas sin necesidad de licencia, y la libertad para ejercer cualquier oficio sin examen, tributo o incorporación al gremio respectivo'. Asimismo, durante la guerra de independencia se expidieron diversos decretos con el mismo propósito". Juan Felipe Leal y José Woldenberg, Del Estado liberal a los inicios de la dictadura porfirista. México, Siglo XXI Editores, Instituto de Investigaciones Sociales, UNAM, $19812^{21} \mathrm{ed.}$ p. 153 (La Clase Obrera en la Historia de México, 2).

${ }^{2}$ Ciro F. S. Cardoso, "Las industrias de transformación (1821-1880)" en C. F. S. Cardoso, et. al., México en el siglo XIX (1821-1910). Historia económica y de la esiructura social, México, Editorial Nueva Imagen, 1980, p. 163-164.

'John M. Hart, El anarquismo y la clase obrera mexicana, traducción de María

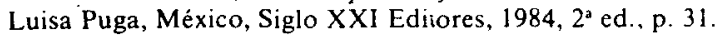


La política económica dominante durante la primera mitad del siglo pasado fue el proteccionismo. Esta orientación en la economía permitió a los artesanos luchar en mejores condiciones contra la invasión de los productos manufacturados extranjeros. Así, en 1843, con el apoyo de Santa Anna, se fundó la Junta de Fomento de Artesanos, cuyos objetivos fundamentales eran defenderse de la competencia extranjera (básicamente de la británica), agrupar a los artesanos para la defensa colectiva de sus intereses, contribuir al aumento y mejoría de la producción manufacturera nacional, participar en la creación de escuelas de enseñanza básica para sus miembros, incluyendo el estudio de las artes y los oficios, mejorar el nivel moral de los artesanos mediante la religión $y$, por último. formar organismos de beneficencia pública.

El capital comercial controlaba la producción artesanal. Desde los primeros años de la centuria decimonónica, la gran mayoría de los talleres se convirtieron en pequeñas unidades productivas trabajadas por su propietario, en las que cada artesano aportaba una parte de las herramientas. Por su parte, el comerciante determinaba el número de piezas que tenía que fabricar cada productor; tenía el control de algunas materias primas (en la producción de textiles, por ejemplo, tenía injerencia en la cosecha del algodón y se hacía cargo de su transportacion). ${ }^{4}$

Paralelamente a la implantación de medidas proteccionistas, se desarrolló un proyecto de financiamiento de las actividades industriales que se concretó en 1830, con la fundación del Banco de Avío. Lucas Alamán y Esteban de Antuñano fueron los artífices de este proyecto. En 1842 se constituyó la Dirección General de Industria, en gran parte obra del propio Alamán, con el objetivo de fomentar y dar apoyo a la industria nacional.

Entre las manufacturas, las textiles fueron las más favorecidas por las medidas gubernamentales. El proteccionismo económico garantizó un espacio en el mercado nacional a los textiles fabricados en México, tratando de hacer menos desigual la competencia con los productos británicos. Pero, por otro lado, el sistema impositivo para la circulación mercantil interna no sufrió modificaciones importantes, constituyendo una limitación para el desarrollo industrial. Al describir el funcionamiento del comercio interregional hacia mediados del siglo xIX, Thomas G. Powell apunta:

Aunque ocasionalmente era posible, el comercio entre las distintas regiones era rara vez practicable, porque además de los altos costos del transporte, los remitentes tenían que pagar altos impuestos sobre sus mercancías. Entre todos los impuestos locales, las alcabalas (impuestos sobre las ventas) eran los que [se] tenían [por] más perniciosos. Los productores y comerciantes pagaban derechos ad valorem del tres al doce y medio por ciento de sus mercancías cada vez que cruzaban una línea divisoria entre dos estados; también pagaban una alcabala de cerca del cinco por ciento al vender la mercancía. Las alcabalas eran exigibles cuando se remitía una mer-

\footnotetext{
4Alejandra Moreno Toscano, "Los trabajadores y el proyecto de industrialización 1810-1867" en Enrique Florescano et al., De la colonia al imperio, $2^{2}$ ed., México, Siglo XXI Editores. Instituto de Investigaciones Sociales, UNAM, 1981, p. 322 (La Clase Obrera en la Historia de México, 1).
} 
cancía, no sólo al entrar a un estado, sino también cuando pasaba de un distrito a otro dentro del mismo estado. Los municipios también cobraban impuestos sobre las ventas. ${ }^{5}$

Evidentemente, el sistema impositivo fue un obstáculo para el desarrollo de una industria enfocada hacia el mercado interno.

A dos niveles las primeras fábricas textiles - mecanizadas - conservaban nexos con el campo. Por una parte, estaban en las haciendas porque todavía no habian roto sus amarras con la propiedad terrateniente. ${ }^{\circ}$ Por la otra, aprovechaban el agua como energía motriz, haciendo necesaria su ubicación en las áreas rurales. ${ }^{7}$ Ejemplo de esto fue la fábrica La Constancia, propiedad de Esteban de Antuñano, instalada en Puebla hacia $1843 .^{8}$

Mediada la centuria pasada, en la capital federal, como en el conjunto del pais, predominaban numéricamente los talleres artesanales sobre las fábricas textiles. Algunos autores afirman que había en México alrededor de 53 de estas fábricas, donde laboraban aproximadamente 12000 trabajadores. $^{9}$

El abasto de materias primas, principalmente algodoón, no estaba garantizado por la producción nacional; era común su importación (o contrabando) de los Estados Unidos. El algodón nacional provenía casi en su totalidad de Veracruz (sería necesario que transcurrieran varias décadas para que la región lagunera viniera en su relevo). La especulación y el acaparamiento eran prácticas comunes en el mercado del algodón. ${ }^{10}$

Los textiles mexicanos poseían escasa competitividad en relación con los ingleses, sólo el proteccionismo gubernamental les permitió entrar en la disputa por el mercado nacional. "Esto significa, en otras palabras, que el consumidor popular financiaba la artesanía, las fábricas textiles y un sector agrícola algodonero poco dinámico". ${ }^{11}$

Al parecer, el impacto producido por la mecanización de la industria textil fue mayor en los hilados, donde desplazó a parte de los artesanos. En el tejido seguía predominando el trabajo de productores autónomos, es decir, el sistema de encargos. ${ }^{12}$ Este hecho constituye un importante indicador del tipo de máquiinas que fueron incorporadas a la industria, máquinas que cumplían sólo las fases primarias del proceso productivo y no el proceso en su conjunto. Aunque había producción mecanizada, la industria textil no había salido del periodo manufacturero propiamente dicho. Como afirmó Marx, "el periodo manufacturero... esporádicamente también desarrolla el uso de máquinas, en particular para ciertos procesos primarios simples que hay que ejecutar masivamente y con gran desgaste de energías". ${ }^{13}$

${ }^{5}$ El liberalismo y el campesinado en el centro de México (1850 a 1876), traducción de R. Gómez (Colección SEP/Setentas), México, Secretaría de Educación Pública, 1974, p. 32-33.

${ }^{6}$ Alejandra Moreno Toscano, op. cit., p. 323-324.

'Juan Felipe Leal y José Woldenberg, op. cit., p. 53.

${ }^{8}$ Dawn Keremitsis, La industria textil mexicana en el siglo XIX (Colección SEP/Setentas), México, Secretaría de Educación Publica, 1973, p. 20.

${ }^{9}$ Edelmiro Maldonado, Breve historia del movimiento obrero (Colección Realidad Nacional, 8), $4^{2}$ ed., Culiacán, Universidad Autónoma de Sinaloa, 1981, p. 8.

${ }^{10}$ Ciro F. S. Cardoso, op. cit., p. 162.

11 lbid.

${ }^{12}$ Ibid., p. 161.

${ }^{13}$ Karl Marx, El capital, traducción de Pedro Scaron, 5' ed. (Biblioteca del Pensamiento Socialista), México, Siglo Veintiuno Editores, 1979, vol. II, p. 423-424. 
La utilización de máquinas, hacia mediados del siglo xIX, no implicó una revolución industrial. Cuando menos desde Luis Chávez Orozco, varios historiadores han caracterizado el proceso industrializador que se generó en México a partir de la independencia como una verdadera revolución industrial. ${ }^{14}$ Para aquél, el aspecto más importante de la revolución industrial en el México decimonónico fue la modernización de la técnica dentro de la industria textil. ${ }^{15}$ Los momentos más importantes de esta revolución, previos a la guerra de Reforma, son a juicio de Chávez Orozco los siguientes: 1) el Proyecto Godoy; 2) el Banco de Avío, y 3) la Dirección General de Industria. ${ }^{16}$

A cambio de que se les permitiera introducir en el país materias preparadas de lana y algodón, cuya importación estaba prohibida, José María Godoy, Guillermo Dollar y Jorge Winterton se comprometieron ante el Congreso de la Unión -en 1828- a establecer 1000 telares. ${ }^{17}$ El proyecto nunca se realizó, en parte por la oposición de los artesanos, a quienes perjudicaba directamente la introducción de textiles extranjeros.

El Banco de Avío y la Dirección General de Industria no cumplieron de manera suficiente los objetivos que se perseguian con su creación. La derrota de los "conservadores" en la guerra de Reforma influyó decisivamente en ello, ya que el proyecto económico del liberalismo triunfante se apoyaba en premisas distintas. Durante el Porfiriato cobra un nuevo impulso el proceso industrializador, se logra un importante desarrollo en la producción de textiles y se diversifica regionalmente la industria, pero básicamente el proceso queda atado al capital extranjero.

Desde nuestro punto de vista, para sostener la tesis de que en la primera mitad de la centuria pasada hubo en México una revolución industrial, habria que demostrar, entre otras cosas, la modificación sustancial de las relaciones de producción dominantes. Podemos afirmar que en esos años no se conformó un mercado interno (será en el Porfiriato, por la vía de la intervención estatal, cuando se inicie su proceso constitutivo) ni se operó la subsunción real del trabajo al capital; el proceso industrializador fue aislado, no involucró a todas las ramas de la producción y no cambió el carácter fundamentalmente agrario de la economía mexicana.

Al introducir la maquinaria, los propietarios fabriles trataron de reducir los salarios de sus trabajadores; ése fue el caso de la Fábrica de Rebozos de Seda Tarel y Cía., ubicada en Guadalajara. ${ }^{18}$ La respuesta de los trabajadores no se hizo esperar: el 17 de abril de 1850 cerca de 500 se amotinaron y amenazaron con incendiar la fábrica. $E l$ Universal - publicado en la ciudad de México- informó a sus lectores sobre aquel hecho:

De una carta de Guadalajara, fecha 19 de abril próximo pasado, copiamos lo siguiente: "Voy á poner a uds. al tanto de una ocurrencia que antes de ayer á las seis de la tarde hubo en la fábrica de

\footnotetext{
${ }^{14}$ Véase Luis Chávez Orozco, Historia económica y social de México. Ensayo de interpretación, México, Ediciones Botas, 1938; Alejandra Moreno Toscano, op.cit.; John M. Hart, op. cit.

${ }^{15}$ Luis Chávez Orozco, op. cit.

${ }^{16}$ Ibid. p. 119.

${ }^{17}$ Ibid.

${ }^{18}$ Guadalajara", en El Universal, México, I de mayo de 1850 t. III, núm. 532, p. 4.
} 
rebozos de Tarel. Este es un establecimiento perteneciente á tres señores franceses, en el que se ocupan de 400 a 500 almas entre chicos y grandes. En dicho establecimiento hay oficiales mexicanos que ganan desde 10rs. hasta 2 ps. diarios, al paso que otros ganan un real y real y medio; los primeros ocupaban dos días para hacer un rebozo hace poco tiempo; hoy lo hacen en uno; una parte de éstos y los más pesados ocupan un día y horas, hasta día y medio. Este adelanto es debido a la nueva maquinaria ${ }^{19}$ que han puesto los dueños del establecimiento." 20

Dias después, los patrones comunicaron a los artesanos:

...que iban a rebajar los sueldos á los maestros, para en parte mejorar la suerte de las gentes que ganaban sueldos muy miserables. Los artesanos en general se incomodaron, generalmente hablando, protestaron no volvera á trabajar más'en el establecimiento, pero otros volvieron á continuar sus trabajos; al salir éstos el martes de su trabajo, los aguardaban los que no habían querido trabajar con palos y piedras: los franceses, dos, salieron á la defensa; uno de éstos fue insultado y amenazado, tiró un tiro al aire, huyó el insultador, éste tropezó y cayó, el francés con un palo le hirió la cabeza. En este estado apareció á caballo el comandante del resguardo de esta aduana D. Ignacio Bernal, acompañado de otro á caballo; éste exclamó (habló Bernal) "Pueblo soberano ¿cómo te dejas atropellar? A las armas, ciudadanos, mueran los gringos". El pueblo correspondía diciendo: "mueran los gringos y los ricos, fuego al establecimiento". Los franceses huyeron; uno se salvó bajo un puentecito, metido de agua hasta medio cuerpo; el otro se salvó habiéndose metido á un tendajón, pero al cerrar la puerta para liberarse de la muerte, el lépero que lo seguía más de cerca dejó el puñal clavado en la puerta. La reuníon era mayor de dos mil almas, entre hombres, mugeres y muchachos; todos pedían la muerte de aquellos infelices y la de los ricos; todos pedían el incendio del establecimiento, debido todo a las doctrinas ${ }^{21}$ que algunos han esparcido aquí. ${ }^{22}$

Más adelante, el relator identifica a los "agitadores":

...si el gobierno no toma parte activa en este negocio, los furrieris${ } a s^{23}$ nos van á traer mil males, entre los gritos se repetían, los de "Vivan los artesanos de Guadalajara, que están sostenidos por hombres de importancia que están a su cabeza". En este estado de cosas llegó el jefe político D. Jesús Camareno, ${ }^{24}$ quien obró con la

\footnotetext{
${ }^{19}$ Subrayado nuestro.

${ }^{20}$ Incluso el editorial del periódico está dedicado a este acontecimiento. Véase "Doctrinas disolventes", en el Universal. México, I de mayo de $1850, \mathrm{t}$. 111 , núm. 532, p. 1 .

${ }^{21}$ Subrayado nuestro.

${ }^{22}$ Véase "Doctrinas disolventes", op. cit.

${ }^{23}$ Subrayado nuestro.

24 en la ciudad, las divisiones administrativas llamadas 'cuarteles', cuadriculaban el espacio urbano en pequeñas unidades 'controlables' (no mayores de 20 manzanas), los alcaldes de cada cuartel tenian como función [textualmente] ser los 'padres políticos de la porción del pueblo que se les encomienda'. Este papel les permitía mantener un control bastante preciso de las actividades de la población residente en su zona. Llevaban cuenta de los nuevos residentes - generalmente migrantes- pero sobre.
} 
velocidad del rayo; logró tranquilizar aquellas gentes, habiendo traído preso á palacio al francés que había herido al paisano, se trajo consigo al paisano herido, otra persona de respeto salvó al infeliz francés, que estaba amparado debajo del puente. La pacificación fue debida esclusivamente al jefe político; con éste vino toda la multitud hasta las inmediaciones de palacio, en donde:les persuadió que se retirasen á sus casas; media hora después se repitió el tumulto, el jefe echó mano de la tropa, vista ésta el pueblo se retiró, 25 soldados con un oficial de confianza cuidaron toda la noche el establecimiento, no ocurrió novedad. ${ }^{25}$

Finalmente se logró la conciliación:

...el artesano herido se presentó ayer á monsieūr Dupart confesando que había obrado mal, instigado por otros personages, pedía que se le perdơnase y se le diese en qué trabajar. Dupart ofreció acceder á todo con tal que el artesano hiciese al señor jefe político una confesión tan sencilla y franca como la que le acababa de hacer á él. Todo sigue en paz, los pobres franceses ${ }^{26}$ están tan asustados que sólo á muy pocas personas que merecen su absoluta confianza no les niegan todo lo que les ha sucedido. ${ }^{27}$

La Fábrica de Rebozos de Seda Tarel y Cía. competía con dos o tres decenas de establecimientos fabriles que producían mercancías similares. ${ }^{28}$ En realidad, los talleres de reboceria tenían pocas posibilidades de disputar el mercado a las fábricas; muchos de aquéllos se localizaban:

...en el barrio del Santuario, al norte de la ciudad, eran al despuntar la quinta década propiedad de pequeños artesanos originarios de Guadalajara. La elaboración de rebozos tenía las características y limitaciones propias de la artesanía; se trataba de pequeños talleres donde participaban todos los miembros de la familia, los cuales, desde luego, eran propietarios de los rudimentarios medios de producción. ${ }^{29}$

Ya en 1843 Manuel López Cotilla señalaba la importancia de la producción de rebozos:

todo se aseguraban de que no hubiera 'vagos' y 'holgazanes'. Podían obligar a los padres a que enviaran a sus hijos a la escuela, a mandar a los jóveneś sin empleo a trabajar con 'amos conocidos' y darles trabajo a las mujeres 'de costura' (y vender luego sus productos). Esto quiere decir que el cargo politico otorgaba facultades que permitian conceder beneficios y asegurar empleos". Alejandra Moreno Toscano, op. cit., p. 327-328.

${ }^{25}$ Véase "Doctrinas disolventes", op. cit.

26 “...para 1844 vivían en esta ciudad alrededor de 20 [franceses] y lo mismo se dedicaban al comercio que a los oficios o a profesiones como la medicina o el magisterio." Jaime Olveda, "El monopolio rebocero Guadalajara-Zamora", en Relaciones, año II, núm. 8, Morelia, otoño de 1981 , p. 95. Jean Meyer abunda sobre este tema en "Los franceses en México durante el siglo XIX" en Relaciones, año I, núm. 2, Morelia, primavera de 1980, p. 94-114.

${ }^{27}$ Véase "Doctrinas disolventes", op. cit.

${ }^{28}$ Para 1880 había un total de 38 fábricas de rebozos en Guadalajara. Mariano Bárcena, Descripción de Guadalajara en 1880, Guadalajara, Ediciones ITG, 1954, (Biblioteca Jalisciense), p. 147.

${ }^{29}$ Jaime Olveda, op. cit., p. 94. 
La industria principal de los habitantes de Guadalajara consiste en el curtido de pieles, fábrica de sombreros, estampados de sarazas y tejidos de lana y algodón. Entre éstos el ramo más estendido, de más crédito y consumo en todo el departamento y en los internos de oriente y occidente, es el de la rebocería. ${ }^{30}$

Los rebozos jaliscienses no sólo cubrian la demanda local, se vendian también en Sinaloa, Sonora, Durango y Zacatecas. ${ }^{31} \mathrm{Al}$ especializarse en la producción de rebozos de seda, la fábrica de Tarel competía con los fabricantes de la ciudad de México y Zamora, porque:

Los talleres de Guadalajara confeccionaban, principalmente, rebozos de hilo de baja calidad y los llamados tápalos - chales de calicot listados- que consumían los grupos de escasos recursos económicos [...] Los de seda usados por las mujeres de las clases altas provenían de México; de Zamora se traían otros no menos finos, de dos vistas, que tenían un costo aproximado de veinte pesos. Éstos los venía fabricando Vicente Murguía desde 1833 en un taller que tenía instalado en esa ciudad. ${ }^{32}$

Carlos Tarel - fabricante de origen francés que instaló en 1844, en Guadalajara, un taller de rebozos - fue demandado como plagiario por Vicente Murguía, ya que este último adquirió la patente de la producción de rebozos de dos vistas (otorgada por la Junta de Industria el 23 de diciembre de 1847). Finalmente, ambos fabricantes llegaron a un acuerdo y el francés pudo continuar elaborando el mismo tipo de rebozos. ${ }^{33}$

Durante 1849, Carlos Tarel -en sociedad con otros francesesamplió su empresa, al adquirir una finca y varios talleres por la cantidad de 32 millones de pesos. Fábrica de Rebozos de Tarel y Cía. fue la razón social del nuevo establecimiento. ${ }^{34}$ Rápidamente, los industriales franceses se apropiaron de los mercados local y regional; para 1854 en su fábrica se realizaban procesos de producción complementarios de la manufactura de rebozos, como el teñido de algodón y seda. ${ }^{35}$ Evidentemente se trataba de empresarios capitalistas que reinvertían las ganancias obtenidas en la empresa, que mecanizaron la fábrica y acortaron el proceso de producción.

Los artesanos textiles jaliscienses no estaban preparados para enfrentar la embestida del capital; contaban con una débil organización y con un conocimiento rudimentario del socialismo de Fourier, difundido por aquellos años en Guadalajara.

Hacia 1850 quedó constituida la Compañía de Artesanos de Guadalajara, cuyos objetivos fundamentales eran: 1) facilitar a los artesanos la adquisición de las materias primas necesarias para el ejercicio de su profesión, y 2) crear los fondos indispensables para la formación de una caja garantista. ${ }^{36}$ Se desprende de lo informado por $E l$

${ }^{30}$ Noticias geográficas y estadísticas del departamento de Jalisco, reunidas y coordinadas de orden de gobierno del mismo, por la Junta de Seguriúú Pública, Guadalajara, Imprenta del Gobierno, 1843, p. 25.

${ }^{31}$ Jaime Olveda, op. cit., p. 94.

${ }^{32}$ Ibid, p. 95.

${ }^{33}$ lbid, p. 96.

${ }^{34}$ lbid, p. 97.

${ }^{35}$ Ibid, p. 101.

${ }^{36}$ Reglamento de la Compañia de Artesanos de Guadalajara, Guadalajara, Imprenta de Manuel Brambila, 1850, p. 17. 
Universal que trabajadores miembros de la compañía participaron en el motín o, al menos, influyeron en él.

Resulta obvia la influencia de Fourier en los documentos de la compañía. En el Proyecto de Reglamento se afirma:

Los elementos productores de toda riqueza posible son:

El Trabajo-agente activo.

El Capital-agente pasivo.

El Talento-agente neutro ó regulador.

Estos tres elementos se encierran en uno: LA INDUSTRIA.

La guerra que hoy existe entre el Capital y el Trabajo, da por resultado el desorden y la miseria.

La alianza de estos mismos agentes dará el resultado contrario, el orden y la abundancia. ${ }^{37}$

Como buena parte de las organizaciones artesanales del siglo pasado, la compañia desvinculaba su acción de la política - si es que esto resultaba posible- y tenía como norma eludir cualquier enfrentamiento con el Estado:

...dejando a otros el cuidado de la política, nosotros reconocemos al gobierno del Estado; sea el que fuere; y lejos de entorpecer su administración, coadyuvaremos al engrandecimiento del país por medio del aumento de riqueza que nos propotcione la combinación sistemada de nuestras fuerzas productivas. ${ }^{38}$

Pero el Estado no era neutral y su acción no se reducía a "la política"; intervenía en los conflictos entre trabajadores y propietarios. No resulta extraño, por ende, que en el motín de la fábrica de Tarel fuera el jefe político quien restableciera el orden.

Los trabajadores amotinados, adscritos a procesos productivos todavía de carácter manufacturero y a relaciones capitalistas subordinadas, se asemejan a los "destructores de máquinas" ingleses. ${ }^{39}$ Estos últimos no veían a la máquina como a un enemigo (como fue el caso de los "luditas"), sino amenazaban al patrón con destruirla, o lo hacían, con la intención de obtener concesiones salariales o de otra indole:

Este tipo de destrucción fue un aspecto tradicional y reconocido del conflicto industrial en el periodo del sistema doméstico y manufacturero, y en las primeras etapas de la fábrica y de la mina. No estaba dirigido sólo contra las máquinas, sino también contra la materia prima, los productos terminados o incluso contra la propiedad privada de los patronos, según el tipo de daño que más pudiera afectarles. ${ }^{40}$

Aunque derrotado, el motín de Tarel forma parte de una larga cadena de luchas de los trabajadores mexicanos en defensa del salario. La maquinización de la industria vino ligada a la caída de los

${ }^{37}$ Ibid.. p. 6

${ }^{38}$ Ibid., p. 5 .

${ }^{34}$ Eric J. Hobsbawm, Trabajadores, Estudios de historia de la clase obrera, (Crítica/Historia, 12). (traducción de Ricardo Pochtar), Barcelona, Editorial Crítica, 1979, p. 19. (c) Ibid. 
jornales y la homogeneización de la fuerza de trabajo; a causa de ello los maestros y el conjunto del artesanado fueron irremediablemente afectados. La Fábrica de Rebozos de Tarel y Cía. constituyó una punta de lanza de la producción propiamente capitalista, con un entorno compuesto por formas productivas poco desarrolladas. ${ }^{41} \mathrm{El}$ conflicto que hemos relatádo se inscribe en la prolongada transición al capitalismo en México.

${ }^{41}$ la producción textil por parte de los artesanos y campesinos nativos [fue] destruida gradualmente en esos paises [semicapitalistas y precapitalistas] al mismo tiempo que la industria doméstica que surgía se combinaba frecuentemente con la industria fabril propiamente dicha. El capital extranjero, por supuesto, afluyó a los países que empezaban a industrializarse, pero fue incapaz de dominar en ellos los procesos de acumulación." Ernest Mandel, El capitalismo tardio, traducción de Manuel Aguilar Mora), México, Ediciones Era, 1979, p. 50 (Colección El Hombre y su Tiempo). 